\title{
Electromagnetic properties of Carbon-Graphene Xerogel, Graphite and Ni-Zn Ferrite composites in polystyrene matrix in the X-Band $(8.2-12.4 \mathrm{GHz})$
}

\author{
Matheus Carvalho Bispo ${ }^{1,2}$, Braulio Haruo Kondo Lopes ${ }^{3}$, Beatriz Carvalho da Silva Fonseca ${ }^{3}$, \\ Roberto Camargo Portes ${ }^{4}$, Jorge Tadao Matsushima ${ }^{5}$, Míriam Kasumi Hwang Yassuda ${ }^{2}$, \\ Gisele Amaral-Labat ${ }^{6}$, Maurício Ribeiro Baldan ${ }^{3}$, Antonio Carlos da Cunha Migliano ${ }^{2}$
}

\footnotetext{
${ }^{1}$ Graduação em Engenharia Mecânica, Instituto Federal de Educação, Ciência e Tecnologia de São Paulo - IFSP, CEP: 12223-201, São José dos Campos, São Paulo, Brasil.

${ }^{2}$ Laboratório de Sistemas Eletromagnéticos, Instituto de Estudos Avançados - IEAv, CEP: 12228-001, São José dos Campos, São Paulo, Brasil.

${ }^{3}$ Laboratório Associado de Sensores e Materiais, Instituto Nacional de Pesquisas Espaciais - INPE, CEP: 12227-010, São José dos Campos, São Paulo, Brasil.

${ }^{4}$ Departamento de Química dos Materiais, Instituto Tecnológico de Aeronáutica - ITA, CEP: 12228-900, São José dos Campos, São Paulo, Brasil.

${ }^{5}$ Faculdade de Tecnologia de São José dos Campos - FATEC SJC, CEP: 12247-014, São José dos Campos, São Paulo, Brasil.

${ }^{6}$ Departamento de Engenharia Metalúrgica e de Materiais, Universidade de São Paulo - USP, CEP: 05508-030, São Paulo, São Paulo, Brasil.

e-mail: matheus.bispo@aluno.ifsp.edu.br, brauliohkl@gmail.com, beatrizalpinopolis@gmail.com, robertocportes@gmail.com, jtmatsushima@yahoo.com.br,miriam@ieav.cta.br, gisele.amarallabat@gmail.com, mauricio.baldan@inpe.br, migliano@ieav.cta.br
}

\begin{abstract}
The electromagnetic properties of Carbon-Graphene Xerogel (CGX), Flaky graphite (GR) and Nickel-Zinc ferrite (FeNiZn) composites in polystyrene (PS) matrix were studied in the X-Band range $(8.2-12.4 \mathrm{GHz})$. In this work the Expanded Polystyrene (EPS) waste material was processed into polystyrene through the recycling of EPS. The polystyrene obtained was utilized as dielectric matrix, mainly because PS is a wellknown organic polymer that presents low dielectric loss and light weight, which contribute to applications in composites for the aerospace field. In order to produce the final composite specimens, the CGX additive was previously synthesized through a sustainable method that employed the use of waste from the paper and pulp industry (black liquor). Afterwards, the morphological and structural analysis were made through Scanning Electron Microscope (SEM) and Raman Spectrometer, respectively. On the other hand, the magnetic ferrite material, FeNiZn, was obtained for the composite production through calcination, whereas the GR utilized was commercially obtained. It was observed that the increase of CGX and GR influenced on the increase of the Complex Permittivity, and that $10 \mathrm{wt} \%$ CGX $+50 \mathrm{wt} \%$ FeNiZn composite sample demonstrated an absorption peak at $10.5 \mathrm{GHz}$. The results are relevant concerning the recycling of EPS waste through its use as dielectric matrix, thus developing greener and low-weight composite materials to be used in microwave applications.
\end{abstract}

Keywords: Carbon-Graphene. Composite. Recycling. Polystyrene. Microwave.

\section{INTRODUCTION}

Electromagnetic Radiation Absorbing Composites (ERAC) have been studied in the recent years [1-3] due to their applications in the aerospace, military and engineering fields, such as in electromagnetic shielding and sandwich structures. These areas often require materials with low density, heat insulation and chemical stability properties. Regarding composites, it is known that the impedance matching may be improved with the balanced combination of dielectric and magnetic materials, so that the electromagnetic wave (EMW) interacts better with the material $[4,5]$. Carbonaceous materials like Carbon-Graphene Xerogel (CGX) and Natu- 
ral Flaky Graphite (GR) have good mechanical properties, high conductivity and low density [6]. On the other hand, Ni-Zn Ferrite (FeNiZn) contributes to the magnetic behavior of a material with its chemical stability, and heat insulation property [7].

Carbon Xerogels (CX) are materials obtained through the carbonization of organic gels, which are often prepared by the sol-gel method utilizing organic monomers like resorcinol and formaldehyde [8]. It is known that textural characteristics of the CX such as surface area, pore volume and pore size distribution depend strongly on the experimental conditions of the synthesis method chosen [9]. Obtaining this CX is more simplified than other types of carbonaceous materials, such as carbon aerogels. Unlike carbon aerogels, in the CX method drying under natural conditions is employed to make this process not expensive, since the supercritical conditions used in carbon aerogels process induce high operating cost and hazardous handling [10]. Thus, in this work Carbon-Graphene Xerogels (CGX) were materials synthesized through a less costly method which employs the use of waste from the paper and pulp industry, the Kraft black liquor. This sustainable method allowed the incorporation of graphene in the CX structure, bringing the electrical properties of graphene to composites.

Polymers have been showing potential to be used as matrices in aerospace applications due to their low cost, ease of manufacture, light weight, etc [11]. Polystyrene (PS) is an organic polymer known for its extremely low density in dry state, low dielectric loss and excellent electrical resistance [11]. In the organic polymer PS, the phenyl $\left(\mathrm{C}_{6} \mathrm{H}_{5}\right)$ groups play an important role, restricting the rotation of polymeric chains around $\mathrm{C}-\mathrm{C}$ bonds, therefore it brings the rigidity property of the polymer [12]. The low electric properties of polystyrene might be explained due to the nonpolar characteristic of the polymer; it is known that PS has a small dipole moment because of the asymmetry at the phenyl side group [13].

This work is based on the study of the electromagnetic properties of CGX, FeNiZn and GR embedded in polystyrene (PS) matrix in the X-Band $(8.2-12.4 \mathrm{GHz})$. The usage of polystyrene as the polymeric matrix is mainly attributed to its low weight and interesting low dielectric properties $[14,15]$ which are close to other materials commonly utilized as matrix, like silicon rubber and epoxy resin. The present work also aims the recycling of EPS waste material through its use as dielectric matrix for microwave applications. Large quantities of EPS waste are disposed of in landfills [16], and they cannot be decomposed in nature for many generations since EPS waste is fragmented into particles of microplastic, which can be highly environmentally negative to the aquatic life in the world [17]. It was estimated in 2014 that 125,000 tons of EPS were produced and only $1 \%$ was recycled [17].

\section{MATERIALS AND METHODS}

Composite samples with magnetic and carbonaceous additives were produced in order to analyze the electromagnetic properties and study the electromagnetic wave absorption performance of the composites in the X-Band.

\subsection{Materials}

The materials employed for processing the composites were: synthesized Carbon-Graphene Xerogel, Natural Flaky Graphite $(250 \mu \mathrm{m}>$ particulate $>106 \mu \mathrm{m})$ obtained from NACIONAL DE GRAFITE LTDA, Ni-Zn Ferrite $\left(\mathrm{Ni}_{0,8} \mathrm{Zn}_{0,2} \mathrm{Fe}_{2} \mathrm{O}_{4}\right)$ powder obtained through calcination at $900^{\circ} \mathrm{C}$ [18], and Expanded Polystyrene waste. The GR and FeNiZn powders were previously characterized in terms of morphology, structure and chemical composition [18].

\subsection{Methodology}

The materials required for the synthesis of CGX were resorcinol (7.5 g), formaldehyde (22 g), Poly (methyl methacrylate) (PMMA) (22.5 g), Kraft black liquor (50 g) and a commercial graphene dispersed in isopropyl alcohol (1 mL). The Kraft black liquor and the commercial graphene was kindly supplied by Suzano Papel e Celulose S.A. and Carbonium 3 Industria Quimica S.A, respectively. In order to synthesize the CGX, the precursor materials were agitated until a gel structure could be formed, subsequently the mixture was dried under natural conditions. Afterwards, the material was carbonized at $900^{\circ} \mathrm{C}$ under inert atmosphere, and, then, washed with distilled water. The morphological and structural analyses of the synthesized CGX powder were evaluated by Scanning Electron Microscope (SEM) JEOL JSM-5310 and Raman spectrometer HORIBA LabRam HR Evolution with excitation laser wavelength of $514 \mathrm{~nm}$, respectively.

Currently there are various methods of recycling EPS waste [19], in this work the recycling method adopted was comprised of the dissolution of EPS [20] in acetone which is a non-solvent. Expanded Polystyrene waste 
materials were weighed and reduced to Polystyrene (PS) by diluting the EPS waste in acetone at the ratio of $0.62 \mathrm{~g} / \mathrm{ml}$; subsequently composite samples 3-mm thick of CGX, FeNiZn and GR embedded in PS matrix were manufactured in different weight concentrations (Tab. 1). The mixtures of randomly dispersed particulates, for the composite specimens followed the dimensions of a $1 / 4$ Wavelength Shim, with width of 22.86 $\mathrm{mm}$, height of $10.16 \mathrm{~mm}$ and maximum thickness of $9.78 \mathrm{~mm}$.

Table 1: Composition of the composite samples produced.

\begin{tabular}{c|l}
\hline SAMPLE & \multicolumn{1}{|c}{ COMPOSITION } \\
\hline 1 & Pure PS \\
\hline 2 & $50 \mathrm{wt} \%$ FeNiZn \\
\hline 3 & $10 \mathrm{wt} \%$ CGX \\
\hline 4 & $10 \mathrm{wt} \%$ GR \\
\hline 5 & $50 \mathrm{wt} \%$ FeNiZn $+10 \mathrm{wt} \% \mathrm{CGX}$ \\
\hline 6 & $50 \mathrm{wt} \%$ FeNiZn $+10 \mathrm{wt} \% \mathrm{GR}$ \\
\hline
\end{tabular}

The complex permittivity, complex permeability and reflection loss of the composites were measured in the frequency range from 8.2-12.4 GHz by using a Vector Network Analyzer (VNA) with a rectangular waveguide, and the X11644A X-Band Waveguide calibration kit was used throughout the electromagnetic measurements. The reflection loss of the samples 5 and 6 was also calculated in order to estimate the effect of thickness change on absorption, varying from $2.5 \mathrm{~mm}$ to $3.5 \mathrm{~mm}$. The calculus was made by the Reflection Loss (RL) and Intrinsic Impedance [4, 5], referring to Eq. (1) and Eq. (2), respectively.

$$
\begin{aligned}
& R L=20 \log _{10}\left|\frac{Z_{i n}-Z_{0}}{Z_{i n}+Z_{0}}\right| \\
& Z_{\text {in }}=Z_{0} \sqrt{\frac{\mu_{r}}{\varepsilon_{r}}} \tanh \left\{j\left(\frac{2 \pi f t}{c}\right) \sqrt{\mu_{r} \varepsilon_{r}}\right\}
\end{aligned}
$$

\section{RESULTS AND DISCUSSION}

\subsection{SEM Characterization}

The micrograph in Fig. 1 (a) corresponds to graphene of commercial origin used in the synthesis. The predominant characteristics are the transparency and thin thickness of the graphene sheets [23]. Micrograph of CGX sample is shown in Fig. 1 (b). It is observed that this sample has lamellae in the bulk region, as indicated by the white arrow. Possibly, during the synthesis of CGX, an ordered layer formation occurred in the structure due to the incorporation of graphene material in the mixture.
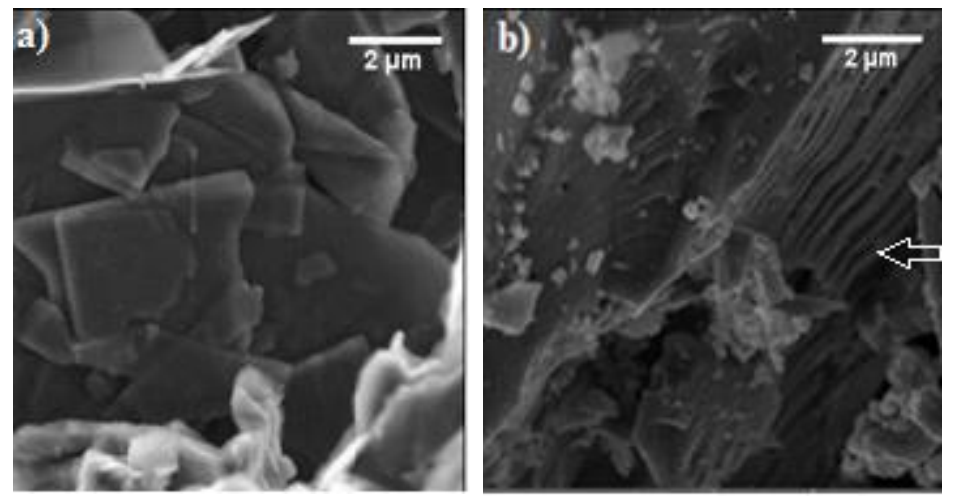

Figure 1: SEM picture of graphene (a), $30.0 \mathrm{kx}$ and SEM picture of CGX (b).

\subsection{Raman Spectroscopy}

The Fig. 2 illustrates the Raman spectra obtained for the CGX and graphene samples. The peaks around 1340 $\mathrm{cm}^{-1}$ and $1580 \mathrm{~cm}^{-1}$ correspond to D and G band, respectively. These peaks are characteristic of carbonaceous 
materials and, in general, defects and disorder are attributed to the $\mathrm{D}$ band. The $\mathrm{G}$ band contributes to the structural integrity of graphite and it is associated with the stretching movement of carbon atoms bonds with $\mathrm{sp}^{2}$. The 2D band present in graphene spectrum can be attributed to the multilayer of graphene [21, 22]. After the insertion of graphene in the CX, an amorphous and defective structure is still prevalent, as already described elsewhere [23], probably because of its amorphous nature, characteristic of a short-range order, is evidenced in the spectrum by the widening of the D and G bands [21].

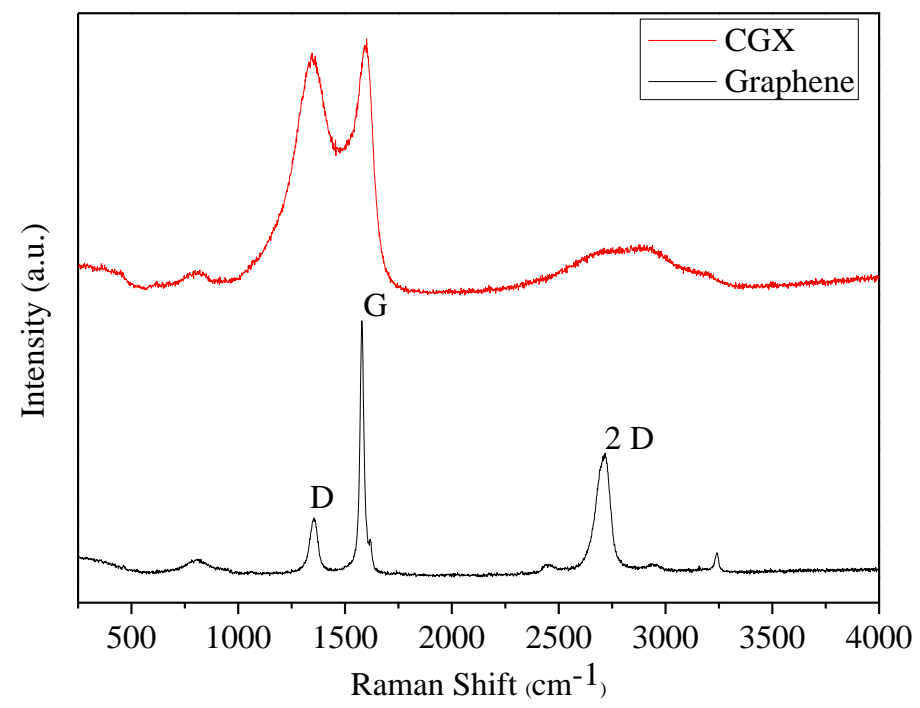

Figure 2: Raman spectra of CGX and graphene samples.

\subsection{Electromagnetic Characterization}

The Complex Permittivity, Eq. (3), and Permeability, Eq. (4), have real ( $\varepsilon^{\prime}, \mu$ ') and imaginary ( $\varepsilon$ ', $\mu$ '”) components that represent the storage of electromagnetic energy and dissipation respectively [5].

$$
\begin{aligned}
& \varepsilon=\varepsilon^{\prime}-j \varepsilon^{\prime \prime} \\
& \mu=\mu^{\prime}-j \mu^{\prime \prime}
\end{aligned}
$$

The real permittivity, Fig. 3 (a), demonstrates, firstly, that the Pure Polystyrene, sample 1, has reduced its capacitive reactance, indicating the EMW almost doesn't interact with it. The sample 1, which represents the specimen composed only by EPS waste material, also demonstrated $\varepsilon$ ' values close to the real permittivity values of the commercial polystyrene [15]. The samples with the mixture of Carbon-Graphene + Ferrite (Sample 5) and Graphite + Ferrite (Sample 6) showed the highest values of $\varepsilon$ ', thus, indicating that the impedance matching, is possibly being favored by the combination of dielectric and magnetic properties. The imaginary permittivity, Fig. 3 (b), demonstrate that all samples have $\varepsilon$ " values between 0.4 and 0.6 within the entire range of frequency, except the sample 1 . The sample 1 have $\varepsilon$ "' values around 0.3 , thus demonstrating the lowest dissipative performance among all samples. 
a)
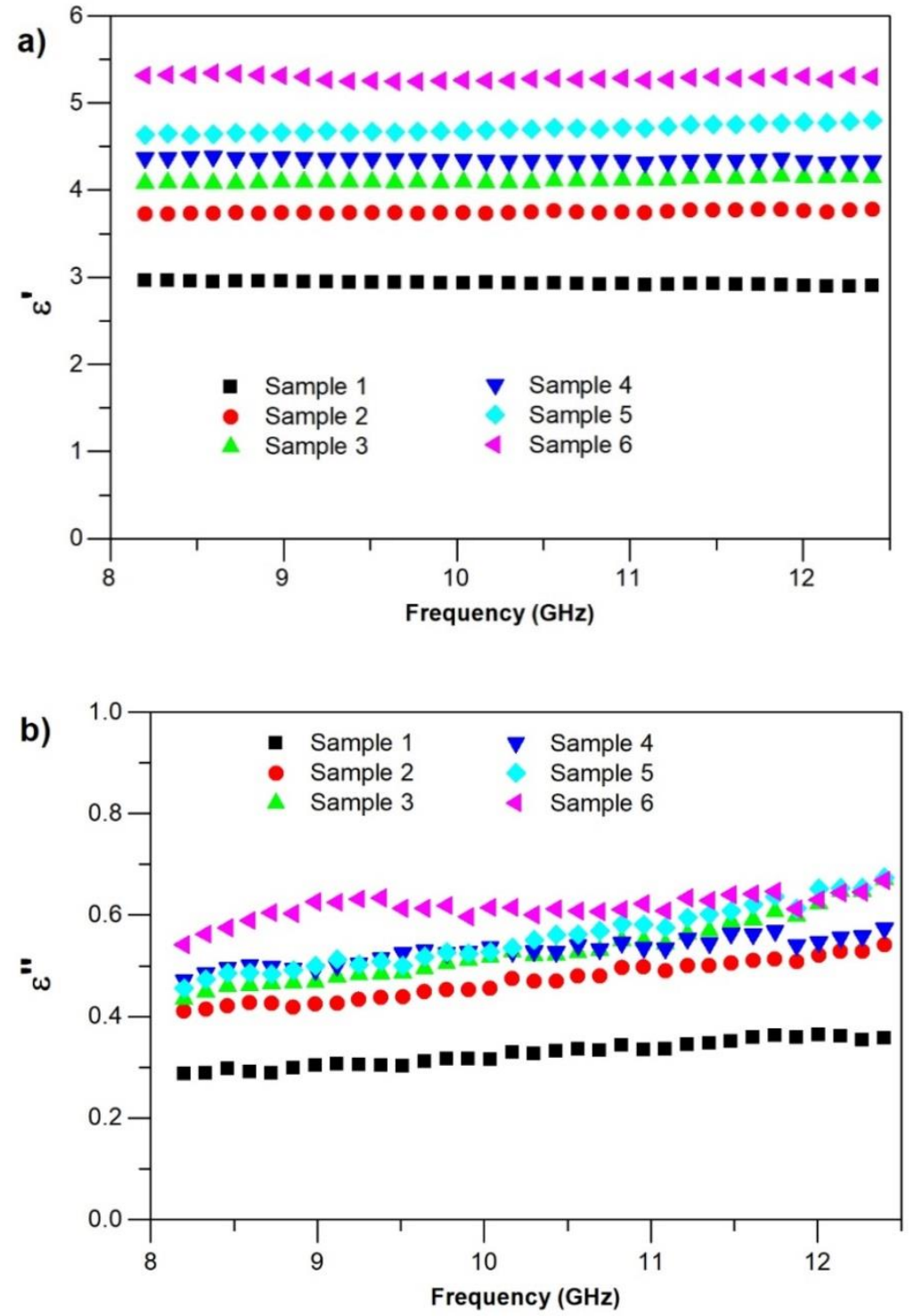

Figure 3: (a) Real Permittivity, (b) Imaginary Permittivity.

The complex permeability, Fig. 4 (a) and Fig. 4 (b), demonstrate that the samples with only the carbonaceous composition can be regarded as dielectric materials since they do not have enough magnetic response to the EMW. However, all the samples with magnetic additive, Ni-Zn ferrite, exhibited lower dielectric response, indicating that $\mu$ ' and $\mu$ ', values are different from 1 and 0 respectively. 

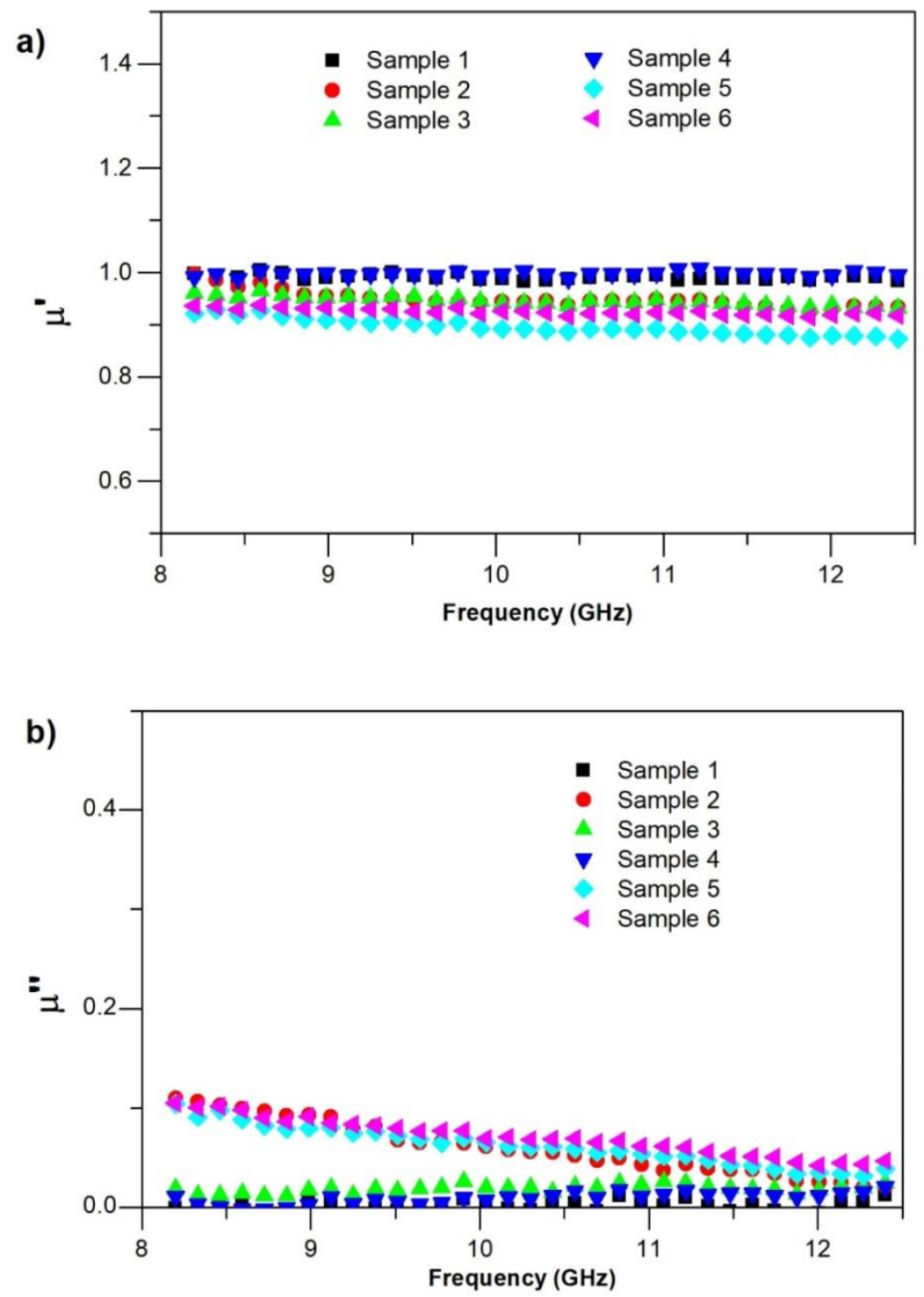

Figure 4: (a) Real Permeability, (b) Imaginary Permeability.

Regarding the RL, Fig. 5, it was verified that the samples with CGX and GR additives exhibited similar absorption, and tendency of resonance effect on higher frequencies in Ku-Band. Samples 5 and 6 showed RL values of $-9 \mathrm{~dB}$, however the sample 6 presented this value in the range $11-12.4 \mathrm{GHz}$, whereas the sample 5 exhibited this RL value at approximately $10.5 \mathrm{GHz}$. Therefore, it can be concluded that the combination of $\mathrm{Ni}-\mathrm{Zn}$ ferrite and both CGX and GR may have contributed to the improvement of the impedance matching performance, thus increasing the absorption. 


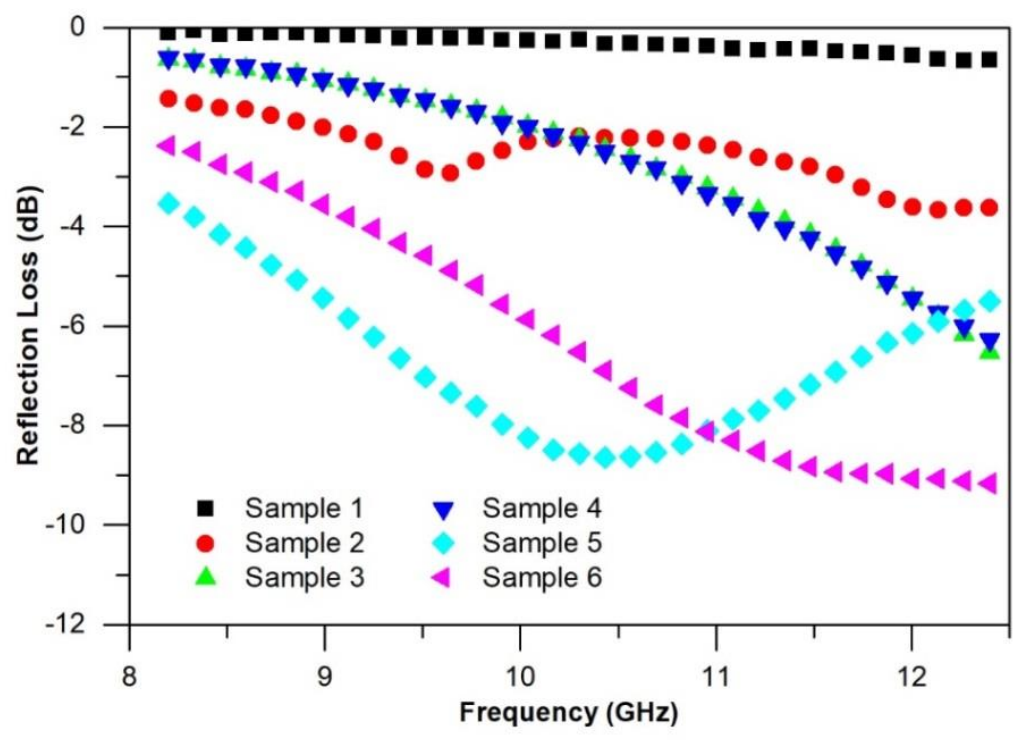

Figure 5: Reflection Loss.

According to the calculated RL values for the sample 5, Fig. 6, it was verified that the highest absorption may occur in thicker specimens, such as in samples $3.5 \mathrm{~mm}$ thick. The 3.5 thickness has RL value of $-7 \mathrm{~dB}$ in the range $10-11.5 \mathrm{GHz}$. It could also be concluded that, the range of frequencies attenuated gets extended, since $3 \mathrm{~mm}$ thickness is increased to $3.5 \mathrm{~mm}$.

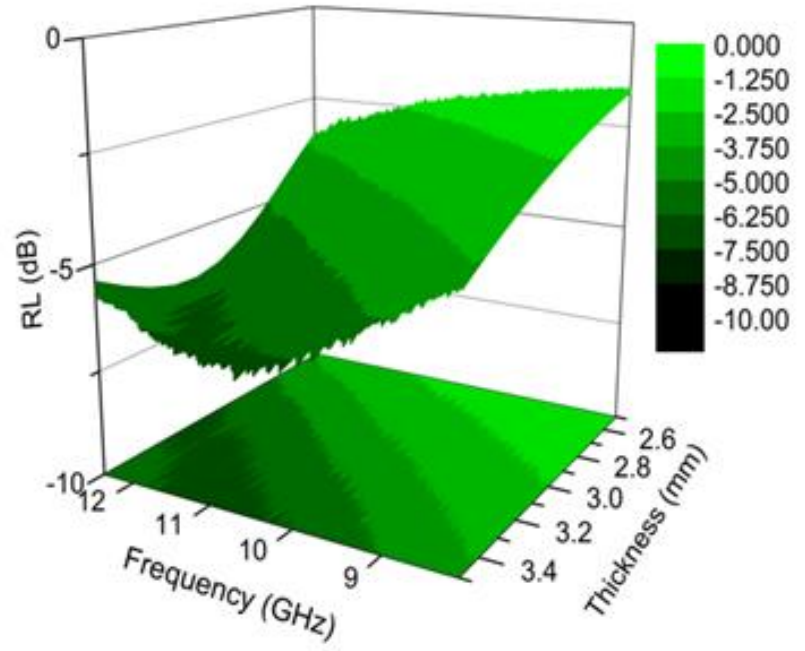

Figure 6: 3D Reflection Loss graph for sample 5 based on thickness variation.

It was observed, for the sample 6, Fig. 7 that the highest absorption peak occurs at approximately $-6.5 \mathrm{~dB}$ in the range $9-10.5 \mathrm{GHz}$ for specimens $3.5 \mathrm{~mm}$ thick, whereas when the thickness decreases to $3.2 \mathrm{~mm}$ for example, the $-6.5 \mathrm{~dB}$ absorption peak appears for a smaller range of frequencies at 10 to $11 \mathrm{GHz}$, indicating that the increase of thickness possibly expanded the absorption band. 


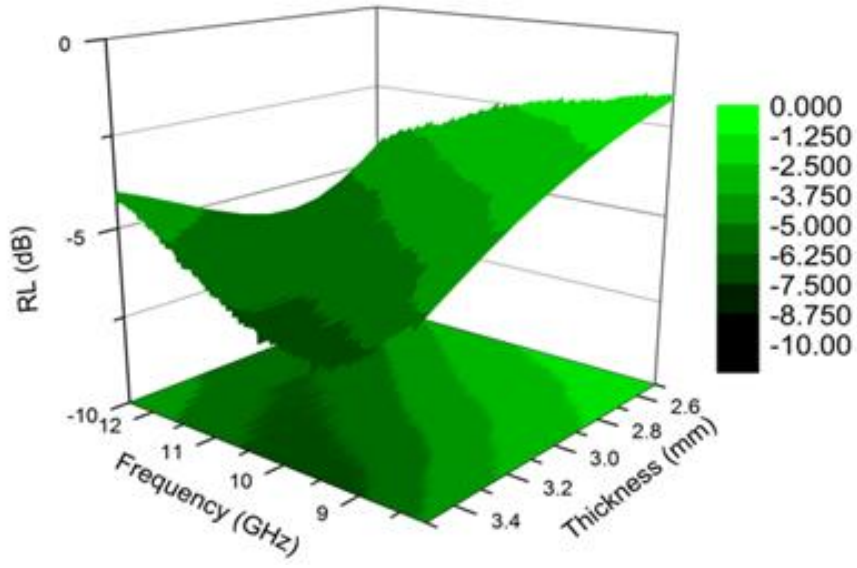

Figure 7: 3D Reflection Loss graph for sample 6 based on thickness variation.

\section{CONCLUSION}

It can be concluded that especially the samples with Carbonaceous materials combined with Ferrites demonstrated the highest absorption values, $-9 \mathrm{~dB}(\approx 87 \%$ absorption), in the X-Band. This phenomenon can possibly be explained by the impedance matching favored by the balanced electromagnetic properties. The RL calculated values demonstrated that, the increase of thickness for both samples 5 and 6 increased the range of frequencies in which the highest absorption occurs. Therefore, in this work the samples with conductive and magnetic additives in a dielectric matrix of PS showed potential to be used as ERAC with highly low weight and thickness, thus transforming the EPS waste into a source of material to be used as dielectric matrix in composites for microwave applications in the aerospace field, and also showing the potential of the Kraft black liquor as an important precursor to the CGX synthesis, making the waste from the paper and pulp industry useful.

\section{ACKNOWLEDGEMENTS}

The authors are grateful for the support of CNPq (project 157234/2019-3) and CAPES.

\section{BIBLIOGRAPHY}

[1] DRAKAKIS, E., KYMAKIS, E., TZAGKARAKIS, G., et al., "A study of the electromagnetic shielding mechanisms in the $\mathrm{GHz}$ frequency range of graphene based composite layers", Applied Surface Science, v. 398, pp. 15-18, Mar. 2017.

[2] KATO, Y., HORIBE, M., ATA, S., et al., "Stretchable electromagnetic-interference shielding materials made of a long single-walled carbon-nanotube-elastomer composite", RSC advances, v. 7, n. 18, pp. 1084110847, Feb. 2017.

[3] ROHINI, R., BOSE, S., "Electrodeposited carbon fiber and epoxy based sandwich architectures suppress electromagnetic radiation by absorption”, Composites Part B: Engineering, v. 161, pp. 578-585, Mar. 2019.

[4] HUANG, X., ZHANG, J., RAO, W., et al., "Tunable electromagnetic properties and enhanced microwave absorption ability of flaky graphite/cobalt zinc ferrite composites", Journal of Alloys and Compounds, v. 662, pp. 409-414, Mar. 2016.

[5] JIA, Z., LAN, D., LIN, K., et al., "Progress in low-frequency microwave absorbing materials", Journal of Materials Science: Materials in Electronics, v. 29, n. 20, pp. 17122-17136, Aug. 2018.

[6] ZHU, Z., SUN, X., XUE, H., et al., "Graphene-carbonyl iron cross-linked composites with excellent electromagnetic wave absorption properties", Journal of Materials Chemistry C, v. 2, n. 32, pp. 6582-6591, Jun. 2014

[7] VALENZUELA, R., "Novel applications of ferrites", Physics Research International, v. 2012, pp. 1-9, Dec. 2011.

[8] PÉREZ-CADENAS, A.F., ROS, C.H., MORALES-TORRES, S., et al., "Metal-doped carbon xerogels for the electro-catalytic conversion of CO2 to hydrocarbons", Carbon, v. 56, pp. 324-331, May. 2013. 
[9] GALLEGOS-SUÁREZ, E., PÉREZ-CADENAS, A.F., MALDONADO-HÓDAR, F.J., et al., "On the micro- and mesoporosity of carbon aerogels and xerogels. The role of the drying conditions during the synthesis processes", Chemical Engineering Journal, v. 181, pp. 851-855, Feb. 2012.

[10] AMARAL-LABAT, G., SZCZUREK, A., FIERRO, V., et al., "Unique bimodal carbon xerogels from soft templating of tannin", Materials Chemistry and Physics, v. 149, pp. 193-201, Jan. 2015.

[11] KAUSAR, A., RAFIQUE, I., MUHAMMAD, B., "Aerospace Application of Polymer Nanocomposite with Carbon Nanotube, Graphite, Graphene Oxide, and Nanoclay", Polymer-Plastics Technology and Engineering, v. 56, n. 13, pp. 1438-1456, Apr. 2017.

[12] SINGH, L., SAMRA, K.S., "Opto-structural characterization of proton (3 MeV) irradiated polycarbonate and polystyrene", Radiation Physics and Chemistry, v. 77, n. 3, pp. 252-258, Mar. 2008.

[13] SASIKALA, T.S., SEBASTIAN, M.T., "Microwave Dielectric Properties of Polystyrene-Forsterite (Mg2SiO4) Composite", Journal of Electronic Materials, v. 45, n. 1, pp. 729-735, 2016.

[14] ARIF, A.R.M., YABAGI, J.A., HUSSIN, M.F., et al., "Synthesis and Microwave Absorption Properties of Doped Expanded Polystyrene with Silver Nanoparticles", Journal of Science and Technology, v. 9, n. 3, pp. 33-40, Dec. 2017.

[15] SILVA, T.I., PEREIRA, I.M., BISPO, M.C., et al., "Estudo das propriedades eletromagnéticas de materiais poliméricos tipo radomes", In: Editora Poisson, Engenharia no Século XXI, 1 ed., chapter 9, Belo Horizonte - MG, Brazil, Editora Poisson, 2019.

[16] SARMIENTO, A.M., GUZMÁN, H.L., MORALES, G., et al., "Expanded Polystyrene (EPS) and Waste Cooking Oil (WCO): From Urban Wastes to Potential Material of Construction", Waste and biomass valorization, v. 7, n. 5, pp. 1245-1254, Feb. 2016.

[17] JIMENEZ-FRANCISCO, M., CAAMAL-CANCHE, J.A., CARRILLO, J.G., et al., "Performance Assessment of a Composite Material Based on Kraft Paper and a Resin Formulated with Expanded Polystyrene Waste: A Case Study from Mexico", Journal of Polymers and the Environment, v. 26, n. 4, pp. 1573-1580, Jun. 2017.

[18] BISPO, M.C., GAMA, A.M., "Caracterização de compósitos absorvedores de radiação eletromagnética na faixa de frequências de micro-ondas em função da temperatura", In: Anais do XV ENICT/IAE, pp. 390-399, São José dos Campos, 2019.

[19] KAN, A., DEMIRBOĞA, R., "A new technique of processing for waste-expanded polystyrene foams as aggregates", Journal of Materials Processing Technology, v. 209, n. 6, pp. 2994-3000, Mar. 2009.

[20] AMIANTI, M., BOTARO, V.R., "Recycling of EPS: A new methodology for production of concrete impregnated with polystyrene (CIP)", Cement and concrete composites, v. 30, n. 1, pp. 23-28, 2008.

[21] LI, Q., et al., "One-step approach for fabrication of 3D porous carbon/graphene composites as supercapacitor electrode materials", Catalysis Today, v. 330, pp. 228-239, 2019.

[22] LIU, Y., et al., "Fabrication of 3D foam-like hybrid carbon materials of porous carbon/graphene and its electrochemical performance", Electrochimica Acta, v. 196, pp. 153-161, 2016.

[23] FONSECA, B. C. S., LABAT, G. A. A., MATSUSHIMA, J. T., et al., "Obtenção de Compósitos Xerogel de Carbono e Grafeno Aplicados como Materiais Eletrocatalíticos", In: Anais do $10^{\circ}$ Workshop em Engenharia e Tecnologia Espaciais (WETE), pp. 26, São José dos Campos, 2019.

\section{ORCID}

Matheus Carvalho Bispo

Braulio Haruo Kondo Lopes

Beatriz Carvalho da Silva Fonseca

Roberto Camargo Portes

Jorge Tadao Matsushima

Míriam Kasumi Hwang Yassuda

Gisele Amaral-Labat

Maurício Ribeiro Baldan

Antonio Carlos da Cunha Migliano https://orcid.org/0000-0002-3029-3938

https://orcid.org/0000-0003-2665-2579

https://orcid.org/0000-0002-7630-7004

https://orcid.org/0000-0002-5316-2965

https://orcid.org/0000-0002-3395-3604

https://orcid.org/0000-0001-6366-1226

https://orcid.org/0000-0003-3745-6119

https://orcid.org/0000-0002-4465-3834

https://orcid.org/0000-0003-1859-7426 